\title{
Imunoglobulinas séricas em crianças com exposição perinatal ao vírus da imunodeficiência humana
}

\author{
Serum immunoglobulins in children perinatally exposed to human immunodeficiency virus
}

\author{
Marcos T.N. da Silva ${ }^{1}$, Maraisa Centeville ${ }^{2}$, Sergio M. Tani ${ }^{2}$, Adyleia A.D.C. Toro ${ }^{3}$, \\ Claudio Rossi ${ }^{4}$, Maria Marluce dos S. Vilela ${ }^{5}$
}

\section{Resumo}

Objetivo: a hipergamaglobulinemia é uma manifestação precoce da infecção perinatal por HIV. O objetivo foi analisar as diferenças nos níveis séricos de imunoglobulinas entre crianças infectadas e sororreversoras, e sua associação com a evolução clínica.

Métodos: em um estudo prospectivo histórico, avaliaram-se 107 crianças infectadas e 90 sororreversoras. Compararam-se: $\operatorname{IgA}$, IgG e IgM entre infectados e sororreversores nos primeiros 18 meses de vida; IgA, IgG e IgM como marcadores indiretos de infecção; IgA, IgG e IgM nos 5 primeiros anos em infectados, de acordo com a evolução clínica. Utilizou-se o teste de Mann-Whitney para a comparação entre grupos. Na avaliação de marcadores indiretos, analisaram-se sensibilidade, especificidade, valores preditivos positivo e negativo, e índice $\mathrm{J}$.

Resultados: infectados, em relação a sororreversores, apresentaram níveis significativamente superiores de $\operatorname{IgM}$, do $1^{\circ}$ ao $5^{\circ}$ trimestre; $\operatorname{IgA}$ e $\operatorname{IgG}$, do $2^{\circ}$ ao $6^{\circ}$ trimestre $(\mathrm{P} \leq 0,05)$. Os níveis de $\operatorname{IgA}$ $\geq 90 \mathrm{mg} / \mathrm{dl} \mathrm{no} 2^{\circ}$ trimestre e $\mathrm{IgG} \geq 1.700 \mathrm{mg} / \mathrm{dl}$ ou $1.200 \mathrm{mg} / \mathrm{dl} \mathrm{no} 2^{\circ}$ e $3^{\circ}$ trimestres associaram-se à infecção por HIV com índices $\mathrm{J}$ de $0,97,0,92$ e 0,93 , respectivamente. Crianças infectadas nas categorias $\mathrm{B}$ e $\mathrm{C}$, comparadas àquelas nas categorias $\mathrm{Ne} \mathrm{A}$, apresentaram níveis superiores de $\operatorname{IgM}$, do $2^{\circ}$ ao $4^{\circ}$ ano e $\operatorname{IgA}$, do $3^{\circ}$ ao $5^{\circ}$ ano $(\mathrm{P} \leq$ $0,05)$.

Conclusões: a evolução temporal dos níveis de $\operatorname{IgA}$, IgG e IgM demonstra um estímulo intenso e precoce à síntese de imunoglobulinas em infectados. Indicadores clínico-epidemiológicos demonstram que tais níveis podem ser marcadores indiretos de infecção. Níveis superiores de $\operatorname{IgMe} \operatorname{IgA}$ do $2^{\circ}$ ao $5^{\circ}$ ano em crianças infectadas com maior gravidade sugerem disfunção na regulação imune secundária ao estímulo antigênico persistente.

J Pediatr (Rio J) 2001; 77 (3): 209-18: síndrome de imunodeficiência adquirida, diagnóstico, imunologia, hipergamaglobulinemia.

\begin{abstract}
Objective: Hypergammaglobulinemia is an early manifestation of perinatal HIV infection. Our objective was to analyze the differences in serum immunoglobulin levels between infected and seroreverter children and their association with clinical outcome.

Methods: we carried out a historical prospective study with 107 infected and 90 seroreverter children. We compared the $\operatorname{IgA}, \mathrm{IgG}$, and IgM levels between infected and seroreverters in the first 18 months of life; IgA, IgG, and IgM as surrogate markers of infection; and $\operatorname{IgA}, \mathrm{IgG}$, and $\operatorname{IgM}$ levels in the first 5 years in infected children, according to clinical outcome. The Mann-Whitney test was used for comparison between groups. Surrogate markers were assessed according to sensitivity, specificity, positive and negative predictive values, and $\mathbf{J}$ index.

Results: infected children, when compared to seroreverters, showed significantly higher levels of: $\operatorname{IgM}$ from the $1^{\text {st }}$ to the $5^{\text {th }}$ trimester; IgA and IgG from the $2^{\text {nd }}$ to the $6^{\text {th }}$ trimester $(\mathrm{P} \leq 0.05)$. Levels of $\operatorname{IgA} \geq 90 \mathrm{mg} / \mathrm{dl}$ in the $2^{\text {nd }}$ trimester and $\operatorname{IgG} \geq 1,700 \mathrm{mg} /$ $\mathrm{dl}$ or $1,200 \mathrm{mg} / \mathrm{dl}$ in the $2^{\text {nd }}$ and $3^{\text {rd }}$ trimesters were associated with HIV infection with J indexes of 0.97, 0.92, and 0.93, respectively. Infected children in the $\mathrm{B}$ and $\mathrm{C}$ categories, compared to those in the $\mathrm{N}$ and $\mathrm{A}$, showed higher levels of IgM from the $2^{\text {nd }}$ to the $4^{\text {th }}$ year, and IgA from the $3^{\text {rd }}$ to the $5^{\text {th }}$ year $(\mathrm{P} \leq 0.05)$.

Conclusions: the temporal progression of $\operatorname{IgA}, \operatorname{IgG}$, and $\operatorname{IgM}$ levels showed an early and intense stimulation to the synthesis of immunoglobulin in infected children. Clinical and epidemiological indicators showed that such levels may be surrogate markers of infection. Higher IgM and $\operatorname{IgA}$ levels from the $2^{\text {nd }}$ to the $5^{\text {th }}$ year in more severely infected children suggest a dysfunction in immune regulation secondary to persistent antigenic stimulation.
\end{abstract}

J Pediatr (Rio J) 2001; 77 (3): 209-18: acquired immune deficiency syndrome, diagnosis, immunology, hypergammaglobulinemia.

\footnotetext{
1. Professor Assistente Doutor - Depto. de Pediatria e Centro de Investigação em Pediatria (CIPED) - Faculdade de Ciências Médicas, Universidade Estadual de Campinas (UNICAMP), Campinas, SP.

2. Aluno do Curso de Pós-Graduação - Depto. de Pediatria - FCM-UNICAMP.

3. Mestre em Pediatria - Depto. de Pediatria - FCM-UNICAMP.

4. Professor Assistente Doutor - Depto. de Patologia Clínica, Laboratório de Imunologia - FCM-UNICAMP.
}

5. Professora Livre Docente - Depto. de Pediatria - FCM-UNICAMP. 


\section{Introdução}

A hipergamaglobulinemia é uma das anormalidades imunológicas mais freqüentes e precocemente observadas em lactentes infectados pelo Vírus da Imunodeficiência Humana (HIV) por transmissão vertical. Em estudo prévio, analisando uma série de casos em crianças brasileiras, relatamos a presença de hipergamaglobulinemia em 77\% dos pacientes ${ }^{1}$. Estudos clínico-epidemiológicos enfocando alterações laboratoriais no seguimento de crianças infectadas na Europa, nos Estados Unidos e na África citam uma incidência semelhante. Na coorte acompanhada pelo Estudo Colaborativo Europeu, a elevação dos níveis de imunoglobulinas foi o primeiro sinal detectado em $74 \%$ das crianças infectadas ${ }^{2-4}$.

A infecção perinatal pelo HIV se caracteriza por intensa replicação viral nas primeiras semanas de vida, tendo como alvo células das linhagens linfocitária e monocitária ${ }^{5}$. Em consequiência da agressão viral, o sistema imune desencadeia uma resposta humoral vigorosa. Estudos de produção espontânea de anticorpos em cultura de linfócitos de pacientes pediátricos mostram que $20 \%$ a $50 \%$ da produção total de imunoglobulinas é dirigida a antígenos do $\mathrm{HIV}^{6}$. Tal resposta é dirigida principalmente à glicoproteína gp 120 do envelope, embora todas as proteínas estruturais ou reguladoras apresentem sítios imunogênicos ${ }^{7}$. Devido à persistência do agente infeccioso e sua variabilidade genética, o estímulo para a ativação do sistema B é mantido durante a evolução da infecção. O papel desempenhado pelos anticorpos específicos na proteção do hospedeiro é controverso. Embora uma proporção significativa dos anticorpos secretados tenha ação neutralizante, impedindo a interação do vírus com a célula-alvo, anticorpos opsonizantes podem facilitar a entrada do HIV em células fagocitárias, através dos receptores da região variável de imunoglobulinas $(\mathrm{Fc})^{8}$. Progressivamente, a resposta humoral contribui para a seleção de linhagens resistentes à vigilância imunológica do hospedeiro?

Apesar da intensa síntese de anticorpos desencadeada pela interação entre HIV e hospedeiro, muitos pacientes manifestam deficiências de resposta imune humoral. A avaliação imunológica de crianças infectadas, principalmente a partir do segundo ano de vida, freqüentemente demonstra diminuição na síntese de anticorpos específicos após imunização ${ }^{10}$. A principal expressão clínica da disfunção imune humoral é a suscetibilidade a infecções bacterianas invasivas, uma das causas mais importantes de morbidade e mortalidade nesta população ${ }^{11}$.

Devido à freqüência e precocidade desta alteração imunológica e às dificuldades no diagnóstico da infecção no lactente, grupos de pesquisadores avaliaram a utilidade dos níveis séricos de imunoglobulinas como marcadores diagnósticos indiretos, com resultados conflitantes. Alguns estudos iniciais, tanto isolados como multicêntricos, destacaram seu valor potencial, no período em que o diagnóstico de infecção por HIV em pediatria baseava-se principalmente em testes sorológicos $3,12-16$.
Neste estudo, com dados de uma coorte de pacientes com exposição perinatal ao HIV, objetivamos analisar as diferenças nos níveis séricos de imunoglobulina A ( $\operatorname{IgA}$ ), imunoglobulina $\mathrm{G}(\mathrm{IgG})$ e imunoglobulina $\mathrm{M}$ (IgM) entre crianças infectadas e sororreversoras, nos primeiros 18 meses de vida. Adicionalmente, avaliamos o significado dos níveis de IgA, IgG e IgM como marcadores indiretos de infecção no primeiro ano de vida, com o uso de indicadores epidemiológicos. Em análise particular ao grupo de crianças infectadas, objetivamos caracterizar a associação entre níveis de IgA, IgG e IgM e categorias de evolução clínica nos primeiros 5 anos.

\section{Casuística e Métodos \\ Modelo de estudo}

Estudo prospectivo histórico.

\section{Pacientes}

Os pacientes estudados são componentes de uma coorte de crianças e adolescentes menores de 14 anos, nascidos de mães infectadas pelo vírus da imunodeficiência humana do tipo 1 (HIV-1), em seguimento no Serviço de Imunodeficiência Pediátrica do Hospital das Clínicas da Universidade Estadual de Campinas. A maior parte dos pacientes é proveniente dos 38 municípios da Direção Regional de Saúde de Campinas (DIR-12), área para a qual o hospital é centro de cuidados terciários, abrangendo uma população estimada em 3 milhões de habitantes.

\section{Critérios de inclusão}

Foram utilizados, para a montagem da base de dados, registros de crianças acompanhadas pelo serviço, desde sua implantação (janeiro de 1989) até a data de 31 de julho de 1998. Conforme protocolo clínico-laboratorial, a dosagem dos níveis séricos de imunoglobulinas é programada trimestralmente, nos primeiros dezoito meses, e semestralmente, após esta idade. Foram utilizados dados de 197 pacientes, que tiveram confirmados seu estado de infecção pelo HIV-1 ou soro-reversão, de acordo com os critérios estabelecidos pelos Centers for Disease Control and Prevention $(C D C)$, que foram utilizados como "padrão ouro" para a avaliação epidemiológica ${ }^{17}$. Devido às características da coorte acompanhada, a disponibilidade de dados em cada grupo etário é variável. Para um determinado paciente, que tenha iniciado o seguimento aos dois anos, não há registros correspondentes ao primeiro ano de vida, por exemplo. Foram incluídos na base de dados todos os resultados disponíveis de imunoglobulinas séricas de cada paciente, evolutivamente, correspondendo aos grupos etários abaixo descritos. Nos casos em que mais de uma dosagem de imunoglobulinas fosse disponível para o mesmo paciente, dentro de um determinado grupo etário (trimestre ou semestre), foi utilizada a média aritmética dos resultados. Foram excluídos os registros de pacientes que receberam imunoglobulina intravenosa ou que apresentaram um diagnóstico de infecção perinatal por agentes outros que o HIV. 


\section{Avaliação laboratorial}

As dosagens de imunoglobulinas séricas foram realizadas no Setor de Imunologia do Laboratório de Patologia Clínica do Hospital das Clínicas da Universidade Estadual de Campinas. A determinação dos níveis séricos de imunoglobulina A ( $\operatorname{Ig} \mathrm{A})$, imunoglobulina $\mathrm{G}$ (IgG) e imunoglobulina $\mathrm{M}(\operatorname{IgM})$, durante o período estudado, foi realizada por imunodifusão radial e nefelometria ${ }^{18}$.

\section{Análise das diferenças entre grupos}

\section{Infectados versus sororreversores}

A comparação entre os grupos infectado e sororreversor visou inicialmente analisar a significância das diferenças nos níveis séricos de imunoglobulinas, agrupados trimestralmente, do $1^{\circ}$ trimestre aos 18 meses de idade. Após os 18 meses de idade, os pacientes sororreversores passam a ter acompanhamento clínico semestral e dosagem de imunoglobulinas anual, reduzindo o número de registros neste grupo para análise estatística.

Adicionalmente, foi avaliado o significado dos níveis de IgA, IgG e IgM séricas como marcadores indiretos de infecção no primeiro ano de vida.

\section{Categorias clínicas no grupo de crianças infectadas}

No grupo infectado, foram comparadas as diferenças de níveis de imunoglobulinas séricas, agrupados semestralmente, de acordo com as categorias clínicas propostas pelo CDC em 1994 ${ }^{17}$ : pacientes que, durante sua evolução, se mantiveram assintomáticos ou com sintomas leves (categorias $\mathrm{N}$ ou $\mathrm{A}$ ), versus aqueles que evoluíram para sintomas moderados ou graves (categorias B ou C). A definição da categoria clínica foi feita com base nos diagnósticos clínicos mais recentes, disponíveis no prontuário. Crianças que, durante sua evolução, apresentaram mudanças na categoria clínica, foram classificadas na categoria mais avançada, para efeito de análise. Desse modo, uma criança que aos 10 meses tenha sido classificada na categoria $\mathrm{A}$ e aos 2 anos tenha evoluído para a categoria $\mathrm{C}$, teve todos os seus registros de imunoglobulinas analisados dentro da categoria $\mathrm{C}$.

\section{Metodologia estatística}

Os valores referentes aos níveis séricos de imunoglobulinas não apresentaram uma distribuição do tipo normal na população estudada, sendo então expressos na forma de mediana e percentis. Foi utilizado o teste não-paramétrico de Mann-Whitney na avaliação das diferenças dos níveis de imunoglobulinas entre dois grupos ${ }^{19}$. Para a rejeição da hipótese nula, foram considerados estatisticamente significativos valores de $\boldsymbol{P}$ menores ou iguais a 0,05 .

Para a definição do valor dos níveis de IgA, IgG ou IgM como marcadores indiretos de infecção pelo HIV no primeiro ano de vida, inicialmente foram selecionados os grupos etários, por trimestre, em que se verificaram diferenças significativas entre infectados e sororreversores. Em seguida, foram determinados sensibilidade, especificidade, valor preditivo positivo e negativo ${ }^{20}$. Foi selecionado como nível de corte, em cada trimestre no primeiro ano de vida, aquele que apresentasse o mais alto valor do índice $\mathrm{J}$ de Youden, definido como (sensibilidade + especificidade $1)^{21}$.

A estruturação do banco de dados e a abordagem estatística descritiva e analítica foram realizadas utilizando-se o programa SPSS para Windows, versão 6.0 (SPSS Inc., Chicago, IL, USA).

\section{Considerações éticas}

O projeto de pesquisa em que se insere este estudo foi aprovado pelo Comitê de Ética em Pesquisa da Faculdade de Ciências Médicas da Universidade Estadual de Campinas.

\section{Resultados}

\section{Caracterização da População Estudada}

Dos 197 pacientes cujos registros foram selecionados, 107 ( 55 do sexo masculino e 52 do sexo feminino) foram definidos como infectados. Noventa crianças ( 45 do sexo masculino e 45 do sexo feminino) foram definidas como sororreversoras.

Entre as crianças infectadas, oito encontravam-se na categoria clínica $\mathrm{N}, 25$ na categoria A, 48 na categoria B e 26 na categoria $C$. As medianas das idades de entrada em cada categoria foram, respectivamente, A, 10 meses; B, 18,9 meses e C, 28,1 meses.

\section{Comparação entre os grupos infectado e sororrever- sor}

Diferenças nos níveis séricos de imunoglobulinas

O grupo de crianças infectadas apresentou níveis significativamente superiores de $\operatorname{IgG}$ e IgA séricas totais a partir do $2^{\circ}$ trimestre de vida, em relação ao grupo sororreversor. As três classes de imunoglobulinas atingiram os níveis mais altos entre os 6 e os 9 meses. Os níveis de IgM sérica total mostraram-se significativamente superiores no grupo infectado já no primeiro trimestre. Tais diferenças mantiveram-se significativas durante os primeiros 18 meses de vida, com exceção para os níveis de IgM entre 15 e 18 meses (Tabela 1, Figura 1). Na Figura 1, destaca-se como importante característica a elevação progressiva dos níveis de $\mathrm{IgG}$ sérica entre os 3 e os 6 meses. Neste período, em crianças normais, observa-se fisiologicamente uma queda transitória, em consequiência do catabolismo da IgG materna e da progressiva maturação na produção desta imunoglobulina pelo lactente. Tal perfil fisiológico foi observado no grupo sororreversor. 
Tabela 1 - Níveis séricos de imunoglobulinas em crianças nascidas de mães infectadas pelo HIV, de 0 a 18 meses

\begin{tabular}{|c|c|c|c|c|c|c|}
\hline Idade & 0-3 M & 3-6 M & 6-9 M & 9-12 M & 12-15 M & 15-18 M \\
\hline Número infectados & 8 & 13 & 22 & 20 & 19 & 29 \\
\hline Sororreversores & 42 & 40 & 45 & 44 & 28 & 24 \\
\hline $\operatorname{IgA}(\mathrm{mg} / \mathrm{dl}) *$ infectados & $40(10-152)$ & $113(92-452)$ & $235(20-619)$ & $152(52-498)$ & $149(47-1130)$ & $159(27-410)$ \\
\hline Sororreversores & $15(1-89)$ & $25(7-86)$ & $41(13-107)$ & $42(13-147)$ & $51(14-101)$ & $53(4-176)$ \\
\hline$P \dagger$ & 0,09 & $<0,001$ & $<0,001$ & $<0,001$ & $<0,001$ & $<0,001$ \\
\hline IgG $(\mathbf{m g} / \mathbf{d l}) *$ infectados & $750(411-2440)$ & $1930(1180-3130)$ & $2840(796-7295)$ & $2860(1124-4299)$ & $2600(1060-4180)$ & $2160(1175-4770)$ \\
\hline Sororreversores & $644(384-981)$ & $462(266-1432)$ & 657 (353-1145) & $839(369-1470)$ & $862(559-1415)$ & $933(669-1677)$ \\
\hline$P \dagger$ & 0,11 & $<0,001$ & $<0,001$ & $<0,001$ & $<0,001$ & $<0,001$ \\
\hline IgM $(\mathrm{mg} / \mathrm{dl}) *$ infectados & $120(55-482)$ & $199(91-459)$ & $273(88-1300)$ & $193(85-486)$ & $222(52-607)$ & $154(54-601)$ \\
\hline Sororreversores & $58(29-184)$ & $79(38-247)$ & $88(54-257)$ & $89(46-151)$ & $112(53-284)$ & $122(74-319)$ \\
\hline$P \dagger$ & 0,03 & $<0,001$ & $<0,001$ & $<0,001$ & 0,001 & 0,13 \\
\hline
\end{tabular}

* Valores expressos na forma de mediana, percentis 5 e 95.

$\dagger$ Teste de Mann-Whitney.

Avaliação do valor dos níveis de imunoglobulinas como marcadores diagnósticos indiretos

Os valores referentes a sensibilidade, especificidade, valor preditivo positivo e negativo e índice $\mathrm{J}$ de diferentes níveis de corte de IgA e IgG, do segundo ao quarto trimestre de vida, e de $\operatorname{IgM}$, do primeiro ao quarto trimestre, estão demonstrados na Tabela 2. A sensibilidade e a especificidade para a dosagem de IgA sérica total mostraram-se elevadas a partir do segundo trimestre, com índices J de 0,97, 0,83 e 0,73 no segundo, terceiro e quarto trimestres, respectivamente. Os níveis de IgG também se destacam, com índices J de 0,92 e 0,93 no segundo e terceiro trimestres, respectivamente. Apesar da precocidade de sua elevação, os níveis de IgM apresentaram índices J menos elevados, com os valores respectivos de $0,45,0,73,0,73$ e 0,75 do primeiro ao quarto trimestre.

\section{Associação entre niveis de imunoglobulinas e evolu- ção clínica no grupo infectado}

Observaram-se, no grupo de crianças com evolução para as categorias $\mathrm{B} \mathrm{e} \mathrm{C}$, comparadas àquelas nas categorias $\mathrm{Ne}$ A os seguintes resultados: níveis de IgA sem diferenças significativas nos 2 primeiros anos de vida, e significativamente superiores do terceiro ao quinto ano (com exceção do intervalo entre 48 e 54 meses); níveis de IgM significativamente superiores dos 12 aos 18, e dos 24 aos 48 meses. Não houve diferenças significativas entre os dois grupos do primeiro ao quinto ano, em relação aos níveis de $\operatorname{IgG}$ (Tabelas 3 e 4, Figura 2).

\section{Discussão}

A alteração imunológica mais precoce na coorte estudada, ao compararmos pacientes infectados com sororreversores, foi a presença de níveis significativamente superiores de IgM nos primeiros três meses de vida. Outros relatos apresentam resultados semelhantes, destacando-se o estudo longitudinal francês, em que, adicionalmente, níveis mais elevados de IgM foram observados em sangue de cordão umbilical, no grupo infectado ${ }^{22,23}$. A identificação de níveis elevados de IgM mais precocemente pode ser explicada por ser a IgM a principal imunoglobulina sintetizada pelo recém-nascido e lactente jovem, sendo a maturação na produção de $\operatorname{IgG}$ e IgA mais tardia ${ }^{24}$. O achado de níveis significativamente superiores de IgM no primeiro trimestre pode também sugerir que estes níveis em parte representem produção fetal de IgM, no subgrupo de crianças com infecção intra-uterina. No entanto, a metodologia deste estudo não permite a estimativa desta parcela de pacientes. 

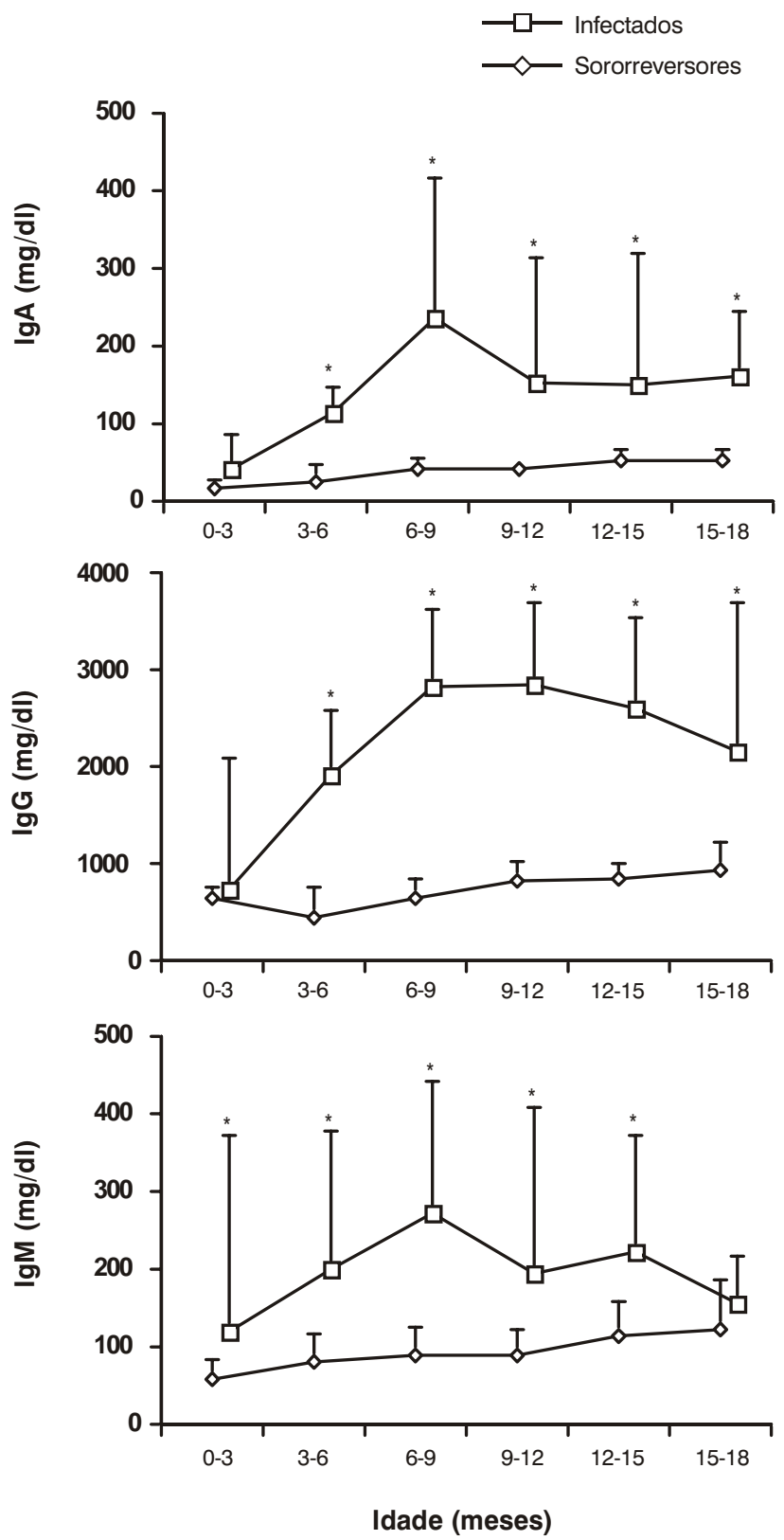

Figura 1 - Evolução dos níveis séricos de imunoglobulinas em crianças com exposição perinatal ao HIV, de 0 a 18 meses. Para melhor visualização, apresentam-se os valores de mediana e percentil 75 . Os asteriscos indicam os grupos etários em que se observaram diferenças estatisticamente significativas

A partir do segundo trimestre, também os níveis de IgA e IgG mostraram-se significativamente superiores. As três classes apresentaram níveis superiores durante o restante do período de comparação (18 meses). Tal situação prova- velmente reflete características já delineadas da resposta de anticorpos na infecção pelo HIV, de gênese multifatorial. A hiperativação dos linfócitos B é uma das alterações imunológicas mais comuns nesta infecção. Tal ativação depende principalmente da glicoproteína gp120, do envelope viral. Este componente induz a síntese de anticorpos neutralizantes específicos ${ }^{9} \mathrm{e}$ também, por atuar como superantígeno, é capaz de causar proliferação de linfócitos B e síntese de anticorpos policlonais. Experimentalmente, tal efeito inespecífico foi demonstrado mesmo em linfócitos de doadores não-infectados ${ }^{25}$. Células com papel central no processo de síntese de anticorpos, como os linfócitos T helper e os macrófagos, sofrem parasitismo direto pelo HIV. Este mecanismo tem o potencial de causar distúrbios na cooperação celular envolvida na síntese de anticorpos ${ }^{11}$.

$\mathrm{Na}$ análise evolutiva dos níveis de imunoglobulinas no grupo de crianças infectadas nos primeiros 18 meses (Figura 1), destacam-se a precocidade da elevação (o pico da resposta se dá entre 6 e 9 meses para todas as classes de anticorpos estudadas), seguida de atenuação da resposta. Tal perfil sugere que um dos estímulos atuantes na resposta humoral seja a replicação viral, com exposição antigênica persistente. A replicação viral inicia-se precocemente no lactente infectado por transmissão vertical, sendo possível na maior parte dos casos detectar DNA viral no sangue periférico entre 2 e 4 semanas de vida. Nas semanas seguintes, ocorre um rápido aumento na viremia, medida pelo número de cópias do RNA do HIV no plasma. Ocorre então uma gradual redução durante os primeiros 2 anos. Neste período, o amadurecimento do sistema imune, com maior capacidade de modulação da resposta celular e humoral, bem como a diminuição relativa do tecido linfóide, provavelmente contribuem para a estabilização da vire$\mathrm{mia}^{26}$.

A atenuação da resposta de imunoglobulinas a partir do $2^{\circ}$ ano de vida pode também refletir os efeitos do tratamento anti-retroviral. No período de acompanhamento da coorte avaliada, os anti-retrovirais utilizados foram principalmente inibidores da transcriptase reversa, como zidovudina (AZT) e didanosina (ddI), isolados ou em associação. Tais drogas têm efeito mais limitado sobre a replicação viral do que os inibidores de protease, mais recentemente introduzidos. O tratamento foi iniciado de acordo com um critério uniforme pelo corpo clínico do serviço, sendo praticamente todos os pacientes tratados a partir do início de sintomas leves. O uso de ddI pode associar-se a uma queda significativa nos níveis de $\operatorname{IgG}$ e na produção de anticorpos pelos linfócitos B, sem associação com parâmetros clínicos ${ }^{27}$. Os esquemas terapêuticos atuais, com a associação de inibidores de transcriptase reversa e de protease, têm o potencial de, inibindo mais significativamente a replicação viral, atuar de forma mais efetiva na modulação da síntese de imunoglobulinas.

O interesse na análise dos níveis de IgA como marcadores indiretos de infecção no lactente justifica-se por não 
Tabela 2 - Sensibilidade, especificidade, valor preditivo positivo e negativo, e índice J de níveis de imunoglobulinas como marcadores indiretos de infecção por HIV em lactentes com exposição perinatal, no primeiro ano de vida

\begin{tabular}{|c|c|c|c|c|c|c|c|}
\hline IDADE & HIV+ & HIV - & Sensibilidade $(\%)^{*}$ & Especificidade $(\%)^{*}$ & V.P.P. $(\%) \dagger$ & V.P. N. $(\%) \%$ & J (Youden) \\
\hline \multicolumn{8}{|l|}{$0-3$ m $(n=50)$} \\
\hline $\mathrm{IgM} \geq 120 \mathrm{mg} \%$ & 4 & 2 & $50(32-68)$ & $95(92-98)$ & 67 & 91 & 0,45 \\
\hline $\operatorname{IgM}<120 \mathrm{mg} \%$ & 4 & 40 & & & & & \\
\hline \multicolumn{8}{|l|}{$3-6 m(n=53)$} \\
\hline $\operatorname{IgA} \geq 90 \mathrm{mg} \%$ & 13 & 1 & 100 & $97(94-100)$ & 93 & 100 & 0,97 \\
\hline $\operatorname{IgA}<90 \mathrm{mg} \%$ & 0 & 38 & & & & & \\
\hline $\mathrm{IgG} \geq 1.700 \mathrm{mg} \%$ & 12 & 0 & $92(85-99)$ & 100 & 100 & 98 & 0,92 \\
\hline $\mathrm{IgG}<1.700 \mathrm{mg} \%$ & 1 & 40 & & & & & \\
\hline $\operatorname{IgM} \geq 140 \mathrm{mg} \%$ & 11 & 5 & $85(75-95)$ & $88(83-93)$ & 69 & 95 & 0,73 \\
\hline $\operatorname{IgM}<140 \mathrm{mg} \%$ & 2 & 35 & & & & & \\
\hline \multicolumn{8}{|l|}{$6-9 m(n=67)$} \\
\hline $\mathrm{IgA} \geq 70 \mathrm{mg} \%$ & 20 & 7 & $95(90-100)$ & $84(79-89)$ & 74 & 97 & 0,83 \\
\hline $\operatorname{IgA}<70 \mathrm{mg} \%$ & 1 & 38 & & & & & \\
\hline $\mathrm{IgG} \geq 1.200 \mathrm{mg} \%$ & 21 & 1 & $95(91-99)$ & $98(96-100)$ & 95 & 98 & 0,93 \\
\hline $\mathrm{IgG}<1.200 \mathrm{mg} \%$ & 1 & 44 & & & & & \\
\hline $\mathrm{IgM}>130 \mathrm{mg} \%$ & 20 & 8 & $91(85-97)$ & $82(76-88)$ & 71 & 95 & 0,73 \\
\hline $\mathrm{IgM}<130 \mathrm{mg} \%$ & 2 & 37 & & & & & \\
\hline \multicolumn{8}{|l|}{$9-12 m(n=64)$} \\
\hline $\operatorname{Ig} \mathrm{A}>60 \mathrm{mg} \%$ & 17 & 7 & $89(82-96)$ & $84(78-90)$ & 71 & 95 & 0,73 \\
\hline $\operatorname{IgA}<60 \mathrm{mg} \%$ & 2 & 37 & & & & & \\
\hline $\mathrm{IgG} \geq 1.300 \mathrm{mg} \%$ & 19 & 3 & $95(90-100)$ & $93(89-97)$ & 86 & 98 & 0,88 \\
\hline $\mathrm{IgG}<1.300 \mathrm{mg} \%$ & 1 & 41 & & & & & \\
\hline $\mathrm{IgM} \geq 170 \mathrm{mg} \%$ & 15 & 0 & $75(65-85)$ & 100 & 100 & 90 & 0,75 \\
\hline $\operatorname{IgM}<170 \mathrm{mg} \%$ & 5 & 44 & & & & & \\
\hline
\end{tabular}

* Valores expressos em porcentagens, com intervalos de confiança para 5\% e 95\%.

† Valor Preditivo Positivo, em porcentagem.

‡ Valor Preditivo Negativo, em porcentagem.

haver passagem transplacentária significativa desta imunoglobulina, bem como por sua maturação tardia em condições normais. A detecção de níveis circulantes elevados de IgA no recém-nascido ou lactente jovem pode ser verificada em algumas infecções congênitas, como a toxoplasmose, porém com sensibilidade variável ${ }^{28}$. A alta prevalência e a intensidade da elevação dos níveis de $\operatorname{IgA}$ a partir do $2^{\circ}$ trimestre de vida, observada na coorte estudada, podem fornecer dados auxiliares para o diagnóstico da infecção. Cumpre destacar que, nesta população, apesar de potenciais dificuldades de análise pela presença de IgG materna circulante, a elevação dos níveis de IgG também demonstrou associação com a infecção por HIV, na análise de indicadores epidemiológicos (Tabela 2). Os resultados de estudos internacionais sobre a utilidade dos níveis de imunoglobulinas como marcadores indiretos de infecção apre- sentam controvérsias. Alguns estudos iniciais, tanto isola-

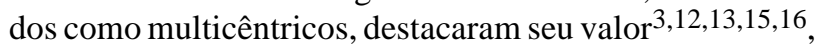
enquanto DeMartino et al., em 1991, ao avaliarem uma coorte de 675 crianças perinatalmente expostas, identificaram níveis significativamente elevados de $\operatorname{IgA}$, IgG e IgM no grupo infectado, em relação a sororreversores, apenas em crianças sintomáticas ${ }^{14}$. Na população estudada, a baixa proporção de pacientes assintomáticos não permitiu explorar este aspecto.

A definição do significado da IgA sérica, como marcador indireto de infecção por HIV pode ser relevante em situações de indisponibilidade de testes laboratoriais específicos. A determinação da presença de IgA específica antiHIV pode fornecer o diagnóstico da infecção aos 6 meses de vida, com sensibilidade de $69 \%$ e especificidade de 

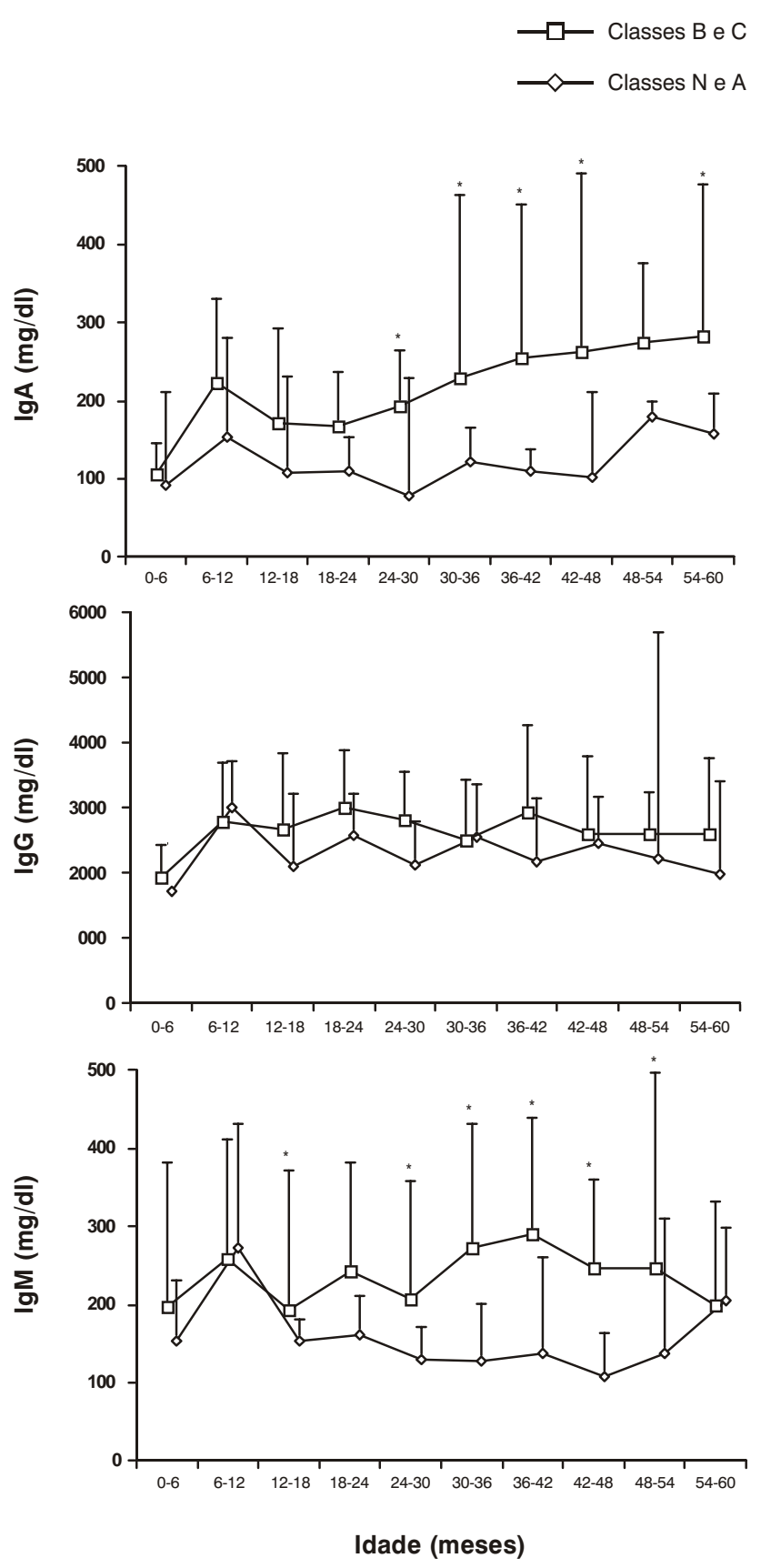

Figura 2 - Evolução dos níveis séricos de imunoglobulinas em crianças infectadas pelo HIV por transmissão vertical, de acordo com categorias clínicas, nos primeiros 5 anos. Para melhor visualização, apresentam-se os valores de mediana e percentil 75 . Os asteriscos indicam os grupos etários em que se observaram diferenças estatisticamente significativas

$100 \%^{29}$. No entanto, testes mais sensíveis, baseados na detecção direta de antígenos virais, como a Reação em Cadeia de Polimerase, que apresenta uma sensibilidade próxima a $100 \%$ no primeiro trimestre, estabeleceram-se, a partir de meados dos anos 90, como os instrumentos de escolha no diagnóstico laboratorial ${ }^{30}$. Tais recursos não estão ainda rotineiramente disponíveis em muitos países em desenvolvimento.

$\mathrm{Na}$ coorte em estudo, crianças que evoluíram com sintomas moderados ou graves, quando comparadas às assintomáticas ou com sintomas leves, apresentaram níveis significativamente superiores de $\operatorname{Ig}$ A e IgM do segundo ao quinto ano de vida. A superioridade dos níveis de IgM mostrou-se mais precoce, já no intervalo de 12 a 18 meses. O principal estímulo para a presença de níveis mais elevados de IgA e IgM nos pacientes que evoluíram com maior gravidade clínica é provavelmente a exposição antigênica provocada pela replicação viral em tecido linfóide. A partir do segundo ano de vida, a progressão para maior gravidade clínica ou óbito está associada à carga viral ${ }^{31}$. Outros mecanismos podem também estar presentes. Pacientes nas categorias $\mathrm{B}$ e C apresentam maior incidência de infecções recorrentes, que podem ser responsáveis, devido ao estímulo antigênico, por níveis mais elevados de anticorpos, notadamente IgM. Estudos em pacientes adultos e pediátricos mostram que aqueles em categorias clínicas mais graves apresentam um predomínio na circulação de citocinas associadas aos linfócitos Thelper do tipo 2, como Interleucina4, Interleucina-6 e Fator de Necrose Tumoral Alfa ${ }^{32}$. Este grupo de citocinas estimula a síntese de imunoglobulinas. Entre as hipóteses propostas para a compreensão específica do mecanismo da elevação dos níveis de IgA sérica, é citada, além dos distúrbios na modulação de citocinas, a redução da expressão de receptores $\mathrm{Fc}$ de IgA em fagócitos, com insuficiente clareamento de imunocomplexos ${ }^{33}$.

A utilidade do acompanhamento dos níveis séricos de imunoglobulinas como marcadores de gravidade da infecção pelo HIV ou preditores de sua evolução clínica tem sido avaliada em coortes de pacientes adultos e pediátricos. Nestes relatos, o surgimento ou a manutenção de níveis elevados, principalmente de IgA, mas também de IgE, têm sido associados a uma evolução clínica desfavorável e a maiores taxas de mortalidade ${ }^{34}$. Dados do Registro Italiano para a Infecção por HIV em Crianças demonstram níveis significativamente mais altos de $\operatorname{IgA}$ e $\operatorname{IgM}$ desde o $1^{\circ}$ mês de vida e elevação progressiva em crianças infectadas com evolução desfavorável, comparadas a crianças com sobrevida maior que $5 \operatorname{anos}^{35}$. Em um estudo africano recente não foi observada associação entre níveis de imunoglobulinas e categorias clínicas. Porém, o modelo de corte transversal utilizado não permite avaliar alterações evolutivas ${ }^{4}$. Em nossa análise, optamos por agrupar todos os registros de cada paciente na categoria clínica correspondente a sua avaliação mais recente. Esta opção permitiu uma avaliação longitudinal, uma vez que as alterações dos níveis de imunoglobulinas freqüentemente precedem, em intervalos variáveis, os sintomas. Método semelhante foi adotado no estudo longitudinal italiano ${ }^{35}$. 
Tabela 3 - Níveis séricos de imunoglobulinas em crianças infectadas pelo HIV, de acordo com categorias de evolução clínica, de 0 a 2 anos

\begin{tabular}{|c|c|c|c|c|}
\hline \multirow[b]{2}{*}{ Categoria } & \multicolumn{4}{|c|}{ Idade } \\
\hline & 0-6 M & 6-12 M & 12-18 M & 18-24 M \\
\hline \multicolumn{5}{|l|}{ Número } \\
\hline $\mathrm{N}+\mathrm{A}$ & 5 & 6 & 9 & 12 \\
\hline $\mathrm{B}+\mathrm{C}$ & 1 & 26 & 30 & 23 \\
\hline \multicolumn{5}{|c|}{$\operatorname{IgA}(\mathrm{mg} / \mathrm{dl}) *$} \\
\hline $\mathrm{N}+\mathrm{A}$ & $91(10-211)$ & $154(78-281)$ & $107(28-230)$ & $110(13-286)$ \\
\hline $\mathrm{B}+\mathrm{C}$ & $106(10-362)$ & $223(36-557)$ & $171(50-499)$ & $167(36-348)$ \\
\hline $\boldsymbol{P} \dagger$ & 0,23 & 0,28 & 0,11 & 0,06 \\
\hline \multicolumn{5}{|c|}{$\operatorname{IgG}(\mathrm{mg} / \mathrm{dl}) *$} \\
\hline $\mathrm{N}+\mathrm{A}$ & $1720(651-1800)$ & $3020(1475-3732)$ & $2105(1250-3235)$ & $2585(1420-3237)$ \\
\hline $\mathrm{B}+\mathrm{C}$ & $1930(603-2708)$ & $2795(884-5375)$ & $2670(1082-4574)$ & $3000(896-7194)$ \\
\hline $\boldsymbol{P} \dagger$ & 0.08 & 0,61 & 0,63 & 0,55 \\
\hline \multicolumn{5}{|c|}{ IgM (mg/dl)* } \\
\hline $\mathrm{N}+\mathrm{A}$ & $154(55-230)$ & $273(83-431)$ & $154(53-182)$ & $161(78-211)$ \\
\hline $\mathrm{B}+\mathrm{C}$ & $198(70-459)$ & $259(106-770)$ & $194(51-780)$ & $243(51-780)$ \\
\hline $\boldsymbol{P} \dagger$ & 0,13 & 0,98 & 0,03 & 0,07 \\
\hline
\end{tabular}

* Valores expressos na forma de mediana, percentis 5 e 95.

$\dagger$ Teste de Mann-Whitney

Concluímos que, nesta coorte de crianças com exposição perinatal ao HIV, foi possível identificar, no grupo infectado, quando comparado ao sororreversor, níveis significativamente mais elevados de IgM (a partir do primeiro trimestre), IgA e IgG (a partir do segundo trimestre). Tais alterações precoces, por apresentarem um perfil temporal semelhante ao da replicação viral no lactente, podem auxi- liar o pediatra, como marcadores indiretos de infecção, na avaliação imunológica da criança com exposição perinatal ao HIV. A presença de níveis mais elevados de IgM e IgA em crianças em categorias clínicas de maior gravidade, a partir do segundo ano de vida, sugere a possibilidade de replicação viral persistente e disfunção progressiva na modulação da produção de imunoglobulinas neste grupo.

Tabela 4 - Níveis séricos de imunoglobulinas em crianças infectadas pelo HIV, de acordo com categorias de evolução clínica, de 2 a 5 anos

\begin{tabular}{|c|c|c|c|c|c|c|}
\hline \multicolumn{7}{|c|}{ Idade } \\
\hline Categoria & 24-30 M & 30-36 M & $36-42 \mathrm{M}$ & 42-48 M & 48-54 M & 54-60 M \\
\hline \multicolumn{7}{|l|}{ Número } \\
\hline $\mathrm{N}+\mathrm{A}$ & 6 & 9 & 8 & 9 & 5 & 6 \\
\hline$B+C$ & 25 & 18 & 9 & 18 & 14 & 16 \\
\hline \multicolumn{7}{|c|}{$\operatorname{IgA}(\mathrm{mg} / \mathrm{dL}) *$} \\
\hline $\mathrm{N}+\mathrm{A}$ & $78(36-229)$ & $121(63-165)$ & $110(73-138)$ & $102(65-211)$ & $180(92-200)$ & $158(111-207)$ \\
\hline $\mathrm{B}+\mathrm{C}$ & $194(52-637)$ & $228(26-654)$ & $255(105-452)$ & $263(77-708)$ & $275(125-690)$ & $283(115-587)$ \\
\hline $\boldsymbol{P} \dagger$ & 0,05 & 0,02 & 0,001 & 0,003 & 0,19 & 0,01 \\
\hline \multicolumn{7}{|c|}{$\operatorname{IgG}(\mathrm{mg} / \mathrm{dL}) *$} \\
\hline $\mathrm{N}+\mathrm{A}$ & $2135(1890-2792)$ & $2550(1720-3360)$ & $2180(1260-3182)$ & $2460(1180-3175)$ & $2230(1510-5710)$ & $1990(1530-3422)$ \\
\hline $\mathrm{B}+\mathrm{C}$ & $2820(1678-5913)$ & $2515(1235-6256)$ & $2950(1605-4281)$ & $2605(1500-5315)$ & $2604(1210-4222)$ & $2615(579-4606)$ \\
\hline $\boldsymbol{P} \dagger$ & 0,21 & 0,82 & 0,17 & 0,43 & 0,96 & 0,64 \\
\hline \multicolumn{7}{|c|}{$\operatorname{IgM}(\mathrm{mg} / \mathrm{dL}) *$} \\
\hline $\mathrm{N}+\mathrm{A}$ & $129(97-172)$ & $128(62-202)$ & $137(78-261)$ & $107(72-164)$ & $138(94-310)$ & 206 (97-298) \\
\hline $\mathrm{B}+\mathrm{C}$ & $207(76-595)$ & $272(81-759)$ & $290(126-439)$ & $247(89-510)$ & $247(79-1106)$ & $200(78-512)$ \\
\hline $\boldsymbol{P} \dagger$ & 0,03 & 0,03 & 0,05 & 0,01 & 0,19 & 0,84 \\
\hline
\end{tabular}

* Valores expressos na forma de mediana, percentis 5 e 95.

$\dagger$ Teste de Mann-Whitney 


\section{Referências bibliográficas}

1. Da Silva MTN, Leitão MF, Lopez N, Mello ALC, Sartorelli CF, Barbosa SM, et al. Características clínicas e laboratoriais de 61 pacientes pediátricos com infecção sintomática pelo HIV. Programa do IX Congresso Brasileiro de Infectologia Pediátrica; 1994 Outubro 8-12; Porto Alegre, RS.

2. Faloon J, Eddy J, Wiener L, Pizzo P. Human immunodeficiency virus infection in children. J Pediatr 1989;114:1-30.

3. European Collaborative Study. Children born to women with HIV-1 infection: natural history and risk of transmission. Lancet 1991;337:253-60.

4. Lyamuya EF, Matee MI, Kasubi M, Scheutz F. Immunoglobulin profile in HIV-1 infected children in Dar-es-Salaam. East Afr Med J 1999;76:370-5.

5. Krivine A, Firtion G, Cao L, Francoual C, Henrion R, Lebon P. HIV replication during the first weeks of life. Lancet 1992;339:1187-9.

6. Amadori A, Chieco-Bianchi L. B-cell activation and HIV-1 infection: deeds and misdeeds. Immunol Today 1990;11:374-9.

7. Björling E, Norrby E. B-cell sites in the HIV glycoproteins. In: Gupta S, ed. Immunology of HIV infection. New York: Plenum Medical; 1996. p. 57-78.

8. Nara P. Humoral immunity to HIV-1: lethal force or trojan horse? In: Gupta S, ed. Immunology of HIV infection. New York: Plenum Medical; 1996. p. 243-76.

9. Parren PW, Moore JP, Burton DR, Sattentau QJ. The neutralizing antibody response to HIV-1: viral evasion and escape from humoral immunity. AIDS 1999;13(Suppl A):S137-62.

10. Peters VB, Mayer LF, Sperber KE. Correlation of in vitro T-cell and B-cell function with responses to childhood vaccines in children with human immunodeficiency virus infection. Viral Immunol 1997;10:197-206.

11. Wilfert CM. Invasive bacterial infections in children with HIV infection. In: Pizzo PA, Wilfert CM, eds. Pediatric AIDS - The challenge of HIV infection in infants, children, and adolescents. Baltimore: Williams \& Wilkins; 1998. p. 117-25.

12. Mok JYQ, Hague RA, Yap PL, Hargreaves FD, Inglis JM, Whitelaw JM, et al. Vertical transmission of HIV: a prospective study. Arch Dis Child 1989;64:1140-5.

13. Monforte AD, Novati R, Galli M, Marchisio P, Massironi E, Tornaghi R, et al. T-cell subsets and serum immunoglobulin levels in infants born to HIV-seropositive mothers: a longitudinal evaluation. AIDS 1990;4:1141-4.

14. DeMartino M, Tovo P, Galli L, Gabiano C, Cozzani S, Gotta C, et al. Prognostic significance of immunologic changes in 675 infants perinatally exposed to human immunodeficiency virus. J Pediatr 1991;119:702-9.

15. Hutto C, Parks WP, Lai S, Mastrucci MT, Mitchell C, Munoz J, et al. A hospital-based prospective study of perinatal infection with human immunodeficiency virus type 1 . J Pediatr 1991;118:347-53.

16. Garcia-Rodriguez MC, Bates I, DeJosé I, Hawkins F, MartinezZapico R, Ferreira A, et al. Prognostic value of immunological data, in vitro antibody production, and virus culture in vertical infection with HIV-1. Arch Dis Child 1995;72:498-501.
17. Centers for Disease Control and Prevention. 1994 revised classification system for human immunodeficiency virus infection in children less than 13 years of age. MMWR 1994;43(RR-12):1-10.

18. Pesce AJ, Frings CS, Gauldie J. Spectral techniques. In: Kaplan AL, Pesce AJ. Clinical Chemistry. 3rd ed. Saint Louis: Mosby; 1996. p. 83-105.

19. Altman DG. Pratical statistics for biomedical research. London: Chapman \& Hall; 1991.

20. Fletcher RH, Fletcher SW, Wagner EH. Clinical epidemiology the essentials. 3rd ed. Baltimore: Williams \& Wilkins; 1996.

21. Youden WJ. Index for rating diagnostic tests. Cancer 1950;3:32-5.

22. Blanche S, Rouzioux C, Moscato MLG, Veber F, Mayaux M-J, Jacomet $\mathrm{C}$, et al. A prospective study of infants born to women seropositive for human immunodeficiency virus type 1 . HIV Infection in Newborns French Collaborative Study Group. N Engl J Med 1989;320:1643-8.

23. Mayaux MJ, Burgard M, Teglas JP, Cottalorda J, Krivine A, Simon F, et al. Neonatal characteristics in rapidly progressive perinatally acquired HIV-1 disease. JAMA 1996;275:606-10.

24. Braun J, Stiehm ER. The B-lymphocyte system. In: Stiehm ER, ed. Immunologic disorders in infants and children. 4th ed. Philadelphia: W.B. Saunders; 1996. p. 35-74.

25. Patke CL, Shearer, WT. gp-120 and TNF-a-induced modulation of human B cell function: proliferation, cyclic AMP generation, Ig production, and B-cell receptor expression. J Allergy Clin Immunol 2000;105:975-82.

26. Luzuriaga K, Sullivan JL. Viral and immunopathogenesis of vertical HIV-1 infection. Pediatr Clin North Am 2000;47:65-78.

27. Pizzo PA, Wilfert CM. Markers and determinants of disease progression in children with HIV infection. The pediatric AIDS Siena workshop II. J AIDS Hum Retrovirol 1995;8:30-44.

28. Decoster A, Darcy F, Caron A. Anti-P30 IgA antibodies as prenatal markers of congenital toxoplasma infection. Clin Exp Immunol 1992;87:310-5.

29. McIntosh K, Comeau AM, Wara D, Diaz C, Landesman S, Pitt $\mathrm{J}$, et al. The utility of IgA antibody to human immunodeficiency virus type 1 in early diagnosis of vertically transmitted infection. Arch Pediatr Adolesc Med 1996;150:598-602.

30. Owens DK, Holodniy M, McDonald TW, Scott J, Sonnad S, et al. A meta-analytic evaluation of the polymerase chain reaction for the diagnosis of HIV infection in infants. JAMA 1996;275:1342-8.

31. Shearer WT, Quinn TC, LaRussa P, Lew JF, Mofenson L, Almy $\mathrm{S}$, et al. Viral load and disease progression in infants infected with human immunodeficiency virus type 1 . N Engl J Med 1997;336:1337-42.

32. Shearer GM, Clerici M. Type 1 and type 2 responses in HIV infection and exposure. In: Gupta S, ed. Immunology of HIV infection. New York: Plenum Medical; 1996. p. 229-42.

33. Grossetête B, Viard JP, Lehuen A, Bach JF, Monteiro RC. Impaired $F c \mu$ receptor expression is linked to increased immunoglobulin A levels and disease progression in HIV-1-infected patients. AIDS 1995;9:229-34. 
34. Multicohort analysis project workshop. Part I. Immunologic markers of AIDS progression: consistency across five HIVinfected cohorts. AIDS 1994;8:911-21.

35. Italian register for HIV infection in children. Features of children perinatally infected with HIV-1 surviving longer than 5 years. Lancet 1994;343:191-5.
Endereço para correspondência:

Dr. Marcos Tadeu Nolasco da Silva

85 Plantation St - aprt. 115 - ZIP 01604

Worcester - MA - USA

Depto. de Pediatria

Tel: (508) 856-3923 - Fax: (508) 856-5500 